\title{
مقامات الناس عند الابتلاء في ضوء القرآن الكريم
}

\author{
مزمل محمد عابدين محمد \\ أستاذ التفسير المساعد- جامعة الإمام المهدي- السودان \\ mozamil.abdeen194@gmail.com
}




\title{
مقامات الناس عند الابتاء في ضيوء القرآن الكريم
}

\author{
مزمل محمد عابدين محمد \\ أستاذ التفسير المساعد- جامعة الإمام المهدي- السودان \\ mozamil.abdeen194@gmail.com
}

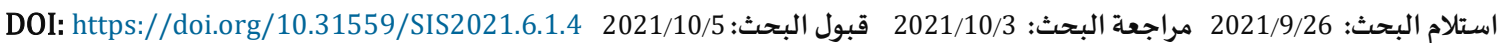

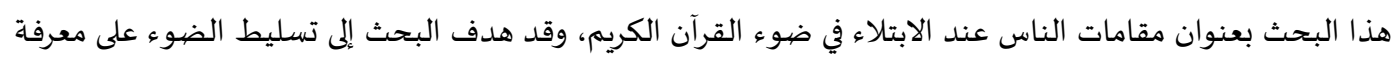

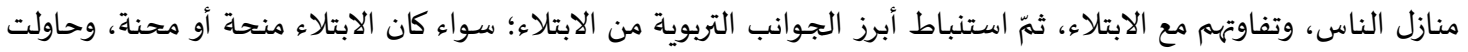

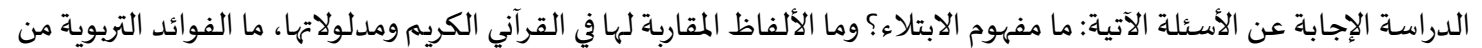 الابتلاء؟ ولتحقيق هذا الهدف سلك الباحث المنهج الاستقرائي والاستنباطي بحيث يعرض الباحث الآنائات الآنات القرآنية التي تناولت

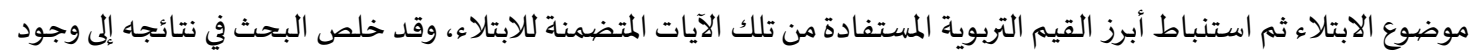

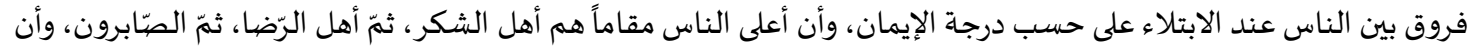

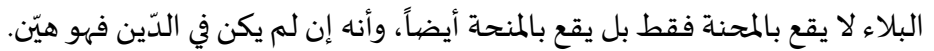 ومن اثار الابتلاء أنها يجعل المسلم جلداً، ذو عزيمة وصبر، ، فالصبر واليقين المين تنال الامامة في الدين.

$$
\text { الكلمات المفتاحية: مقامات الناس؛ الابتلاء؛ القيّم التربويّة. }
$$

إن من السنن الكونية وقوع البلاء على المخلوقين اختباراً لهم، وتمحيصاً لذنوبهم، وتمييزاً بين الصهادق والكاذب منهم قال الله تعالى:

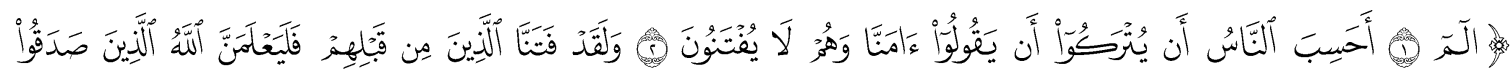

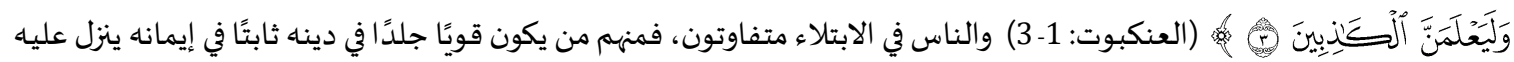

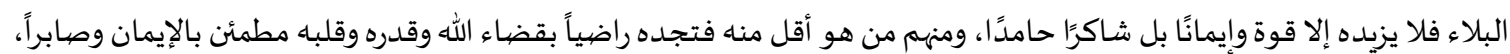

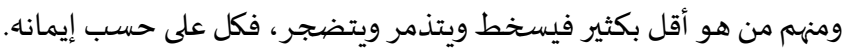

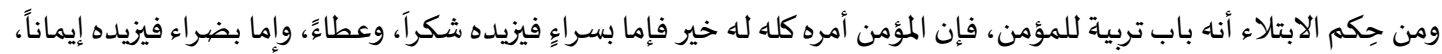

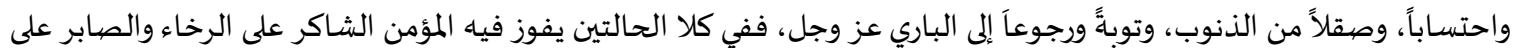
البلاء، ولا يجد الساخط إلاّ سخطاً، وذماً. فلذا أحببت الكتابة في هذا البحث لأن الحياة لا تسير على وتيرة واحدة فلا بد من الاختبار، الرخاء والشدّة، فإن مع العسر يسرًا،

$$
\text { وإن مع العسر يسرًا، أسأل الله العلي القدير أن ييسّر أمورنا. }
$$

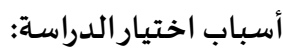

1. ارتباط الموضوع بالغاية من وجود الإنسان وحياته ومستقبله بعد مماته. 2. كثرة البلاء والفتن في زماننا وشدته وقوته. 
3. جهل الناس بالابتلاء ما هو وكيف التعامل معهه وما يتعلق به من أحكام.

مشكلة الدراسة:

تنحصر مشكلة الدراسة في السؤال الرئيس التالي: ما مقامات الناس عند الابتلاء فيما جاءت في نصوص الآيات القر آنية؟

ويتفرع مناه سؤالان :

1. ما معنى الابتلاء في اللغة والاصطلاح؟ وما معانيه في القرآن الكريم؟

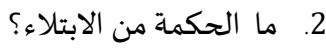

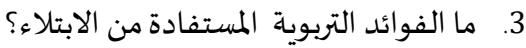

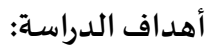

1. تجلية معاني الابتلاء في القرآن الكريم.

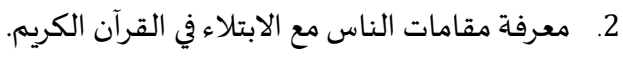

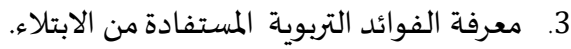

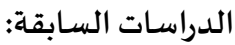

•الابتلاء في القرآن الكريم، إعداد الطالب: باسم محمد محمد سيلان، إشراف الدكتور: عبداللطيف هائل، بحث تكميلي لنيل

درجة الماجستير، جامعة الإيمان.

التربية بالابتلاء - دراسة تربوية لآيات الابتلاء في القرآن الكريم، حمدي سلمان معمر، مجلة جامعة الأقصى (سلسلة العلوم الإنسانية ) المجلد الثالث عشر، العدد الثاني، ص ، ، 121-94 يونيو 2009.

لم استطيع الحصول البحثين السابقين

مفهوم الابتلاء في القرآن الكريم" هدفت الدراسة إلى الكشف عن حكمة الابتلاء وأشكاله وصوره وسـر تنوعاه، وأسبابه وفوائده

المختلفة، وأثره على الشخصية.

الأبعاد التربوية لسنة الابتلاء في ضوء الفكر التربوي الإسلامي

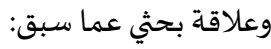

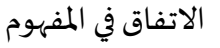

الاختلاف في المحاور، والنتائج.

منهزج الدراسـة وأداتها:

استخدم الباحث في هذه الدراسة المنهج الاستقرائي، والاستنباطي، وكانت أداته تحليل محتوى الأدلة ذات الصلة بالموضهوع ، وما

كتباء علماء التفسير، في الكتابات القديمة والحديثة التي اعتنت، بموضوع الابتلاء، بغية الوصهول إلى أهداف البحث.

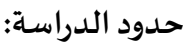

دراسة موضوع الابتلاء من خلال ما ورد من آيات في القرآن الكريم في موضوعاه، وتفسيره بما جاء من بيان قَولي وفعلي لله في سنة

رسوله الكريم - صلى الله عليه وسلم-، وما سطره العلماء، خاصية علماء التفسير.

خطة الدراسة: يحتوي البحث على مقدمة ومبحثين وخاتمة، كما يلي:

المبحث الأول: مفهوم الابتلاء.

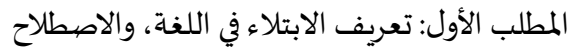

المطلب الثاني: معاني الابتلاء في القرآن الكريم. لمرئ.

المبحث الثاني: حال الناس مع البلاء، وفوائد التربوية مناه. وفياء مطالب:

المطلب الأول: حال الناس مع الابتلاء

المطلب الثاني: فوائد التربوية من الابتلاء الاءول الابتلاء

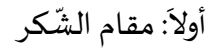

ثانياً: مقام الرضا: مقام الثكار

ثالثاً: مقام الصبر على المصيائب 


$$
\begin{aligned}
& \text { رابعاً: مقام السخط والجزع } \\
& \text { الخاتمة: وفيها أهم النتائج، والتوصيات. } \\
& \text { المبحث الأول: مفهوم الابتلاء } \\
& \text { المطلب الأول: تعريف الابتلاء في اللغة، والاصطلاح }
\end{aligned}
$$

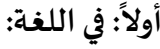

البلاء والابتلاء يلتقيان في معنى الاختبار والامتحان، وهما اسمان من بلاه يبلوه وابتلاه، أي جرَّبه، يقال: "بلوت الرجل بلواً وبلاءً وابتليته: أي اختبرته، وبلاه يبلوه بلواً: إذا جربّهـ واختبره ،(ابن منظور، 14/ 83)، وبُليّ فلان وابتُليَ: إذا امتحن. والبلية والبلوى والبلاء

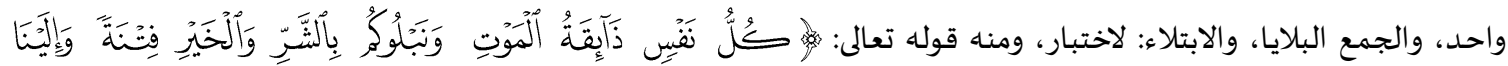

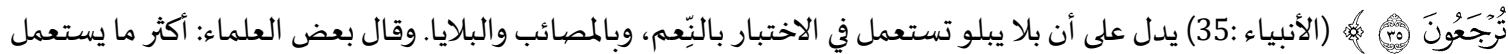
في الشٍِّ بلا يبلو، وفي الخير أبلى يبلي. وقد جمع اللغتين في الخير قول زهير بن أبي سلمى: جزى الله بالإحسان ما فعلا بكم ... وأبلاهما خير

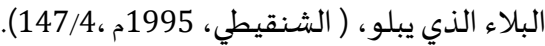
جاء في لسـان العرب: "وقال ابن الأعرابي: أبلى بمعنى أخبر، وابتلاه الله: امتحنـه، والاسـم: البلوى والبلوة والبلية والبلاء، وبُّليَ بالشيء بلاًَ وابتُلي، ( ابن منظور ،

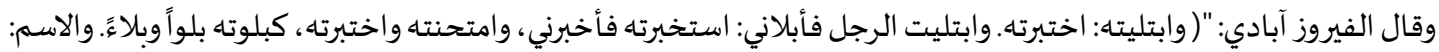

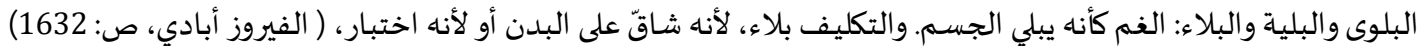
ثانياً: التعريف الاصطلاحي: الابتلاء: "استخراج ما عند المبتلى وتعرف حاله في الطاعة والمعصية بتحميله المشقة، ويقال للنعمة بلاء، لأنها يستخرج بها الشكر،

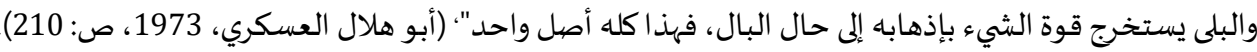

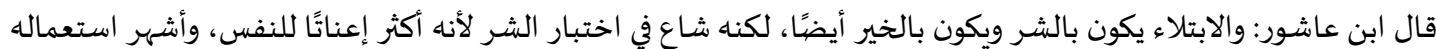

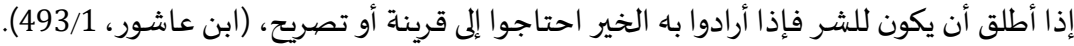

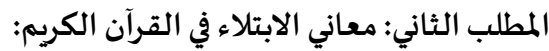
أولاً: بمعنى الامتحان:

أمتحن من المحنة، وكلمة محنة مأخوذة من الفعل محن، والمحندة: الخبرة، وامتحن القول: نظر فيه ودّبّره. ومحنت الفضية إذا

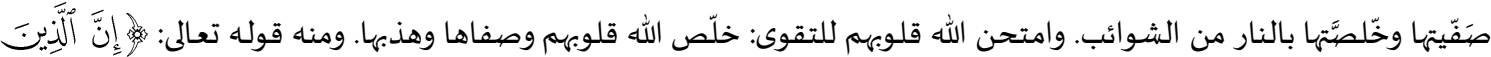

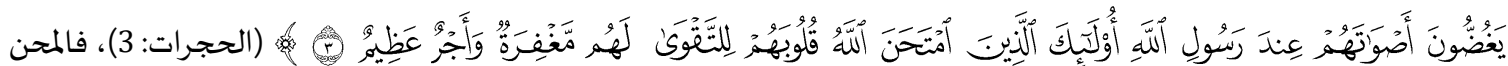
تأتي بمعنى الاختبار لتخليص قلوب المؤمنين وتصفيتها وتنقيتها من الشوائب، وذلك بما أجرى الله عليهم من الأحداث والابتلاءات التي

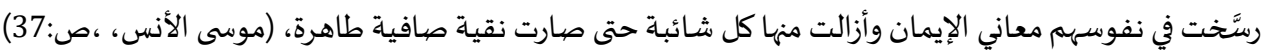
ثانياً: بمعنى الفتنة: قال الراغب: ": أصل الفتن إدخال الذهب النار لتظهر جودته من رداءته، (الراغب، ص: 371) جاء في لسان العرب: "جماع معنى الفتنة: الابتلاء والامتحان والاختبار وأصلها مأخوذ من قولك: فتنت الفضية والذهب: إذا أذبتهما بالنار لتمييز الرديء من الجيد، (ابن منظور، 317/13، الأزهري، (296/1)).

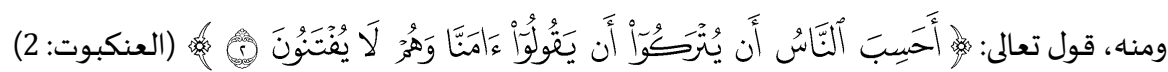
ثالثًا: بمعنى التمحيص:

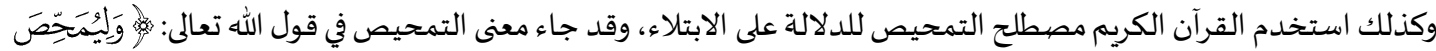

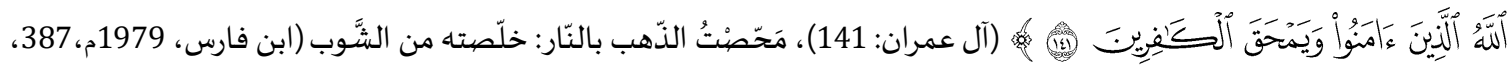

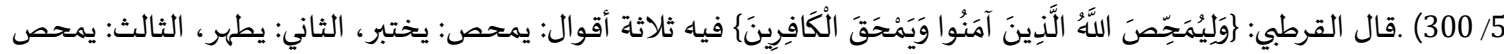


يخلص؛ فهذا أغربها،(القرطبي، 2003 م،4/ 220)، وقال القنوجي: التمحيص الابتلاء والاختبار، وقيل التطهير والتنقية، (القنوجي،

(342 / 1992

رابعاً: بمعنى التكليف:

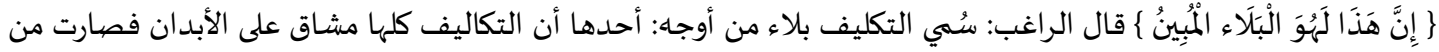

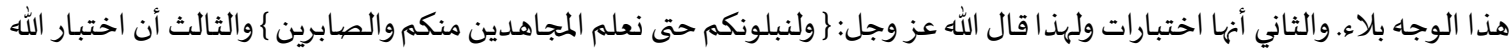

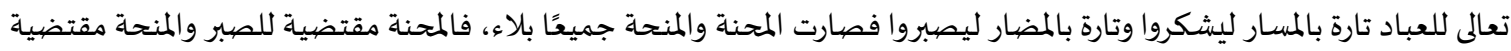

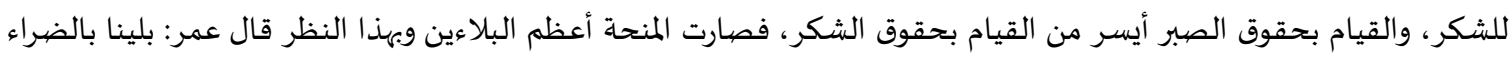

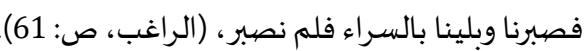
وبعد استعراضنا لمعاني الابتلاء، في القرآن الكريم، يتبين لنا أن هذه الكلمات تلتقي في معنىً واحدٍ هو الاختبار والامتحان.

\section{المبحث الثاني: حال الناس مع البلاء، وفو ائد التربوية منه \\ المطلب الأول: حال الناس مع الابتلاء}

سنتناول هذه المقامات من الأعلى مقاما إلي أقل المقامات مستهدياً بحديث الرسول صلاء الهاء الله عليه وسلم (أن تعبد الله كأنك تراه

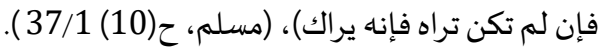

فأول هذه المقامات:

أولاً: مقام الشكر:

فضله: منزلة الشكر من أعلى المنازل وهي فوق منزلة الرضا وزيادة فالرضا مندرج في الشكر إذ يستحيل وجود الشكر بدونه، وهو

نصف الإيمان، فالإيمان نصفان نصف شكر ونصف صبر (ابن القيم،1996م، 232/2 وانظر الشايع 1993 ، ص 224).

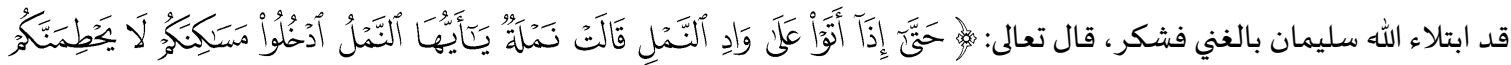

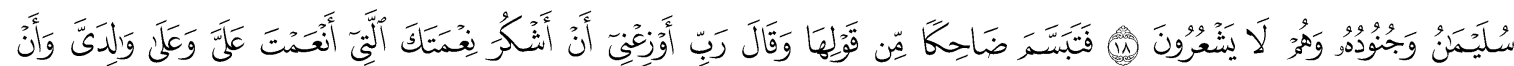

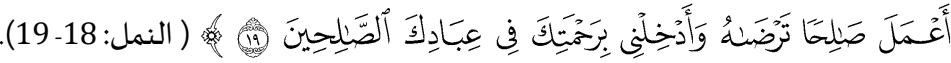

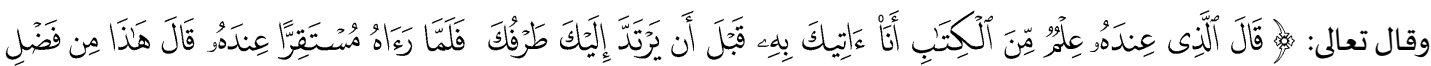

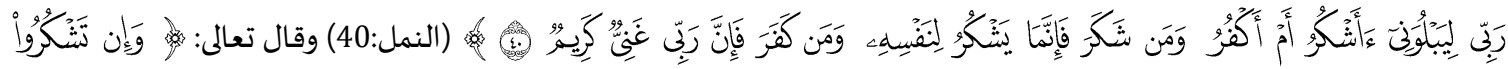

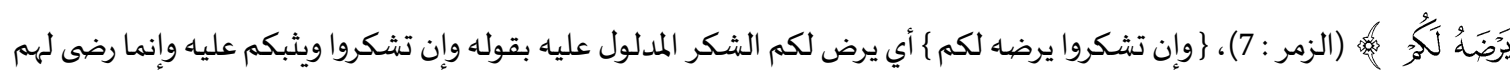
سبحانه الشكر لأنه سبب سعادتهم في الدنيا والأخرة كما قال سبحانه (لئن شكرتم لأزيدنكم) (الشوكاني، 4. 452).

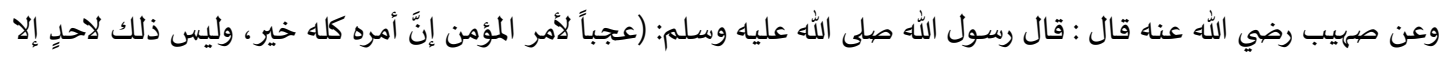

للمؤمن، إنْ أصابته سراء شكر، فكان خيراً له، و إنْ أصابته ضراء صبر فكان خيراً له)، (البيهقي، 116/4، والألباني، حسهـ (147). وعن أبي هريرة رضي الله عنه قال: قال رسول الله صلى الله عليه وسلم (من لا يشكر الناس لا يشكر الله)، (الترمذي، حسراء ح (1954) ).

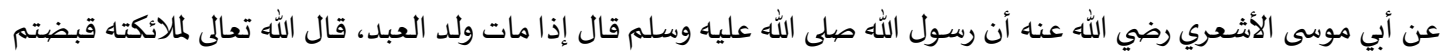
ولد غيري، فيقولون نعم فيقولون قبضتم ثمرة فؤاده فيقولون نعم، فيقول: ماذا قال عبدي؟ فيقولئ إنون : حمدك واسترجع فيقول الله:

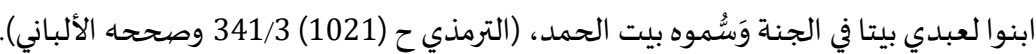

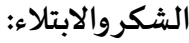
أولًا: الابتلاء بالنعمة: الابتلاء:

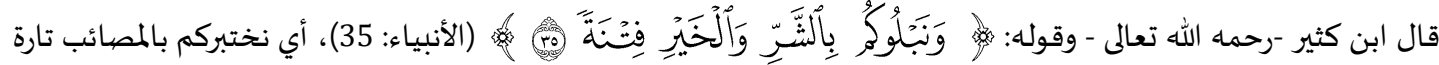
وبالنعم تارة أخرى فننظر من يشكر ومن يكفر ومن يصبر ومن يقنط كما قال علي ابن أبي طلحة عن ابن عباس (ونبلوكم) نبتليكم

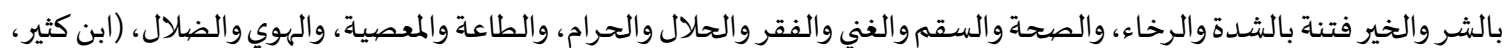

1999 م ،238/3)

قال بعض السلف: البلاء يصبر عليه المؤمن والكافر، ولا يصبر على العافية إلا الصديقون. 
وقال عبد الرحمن بن عوف -ضي الله عنه-: ابتلينا بالضراء فصبرنا وابتلينا بالسراء فلم نصبر ولذلك حذر الله عباده من فتنة المال

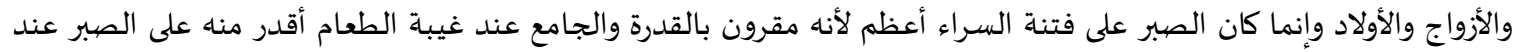

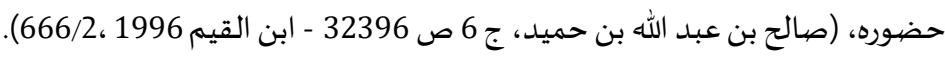
ثانيًا: الابتلاء بالنغمة:

والشكر على المكاره أشـد واصعب من الشكر على المحاب ولهذا فهو فوقها في الدرجة ولكن " كيف يتصور الشكر على البلاء؟ وكيف

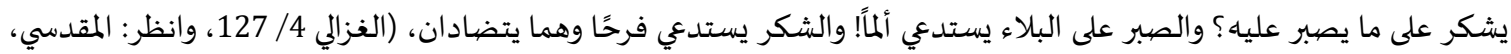

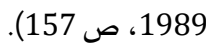

اعلم وفقك الله: أن في كل فقر، ومرض وخوف وبلاء في الدنيا خمسة أشياء ينبغي أن يفرح العاقل بها ويشكر عليها:

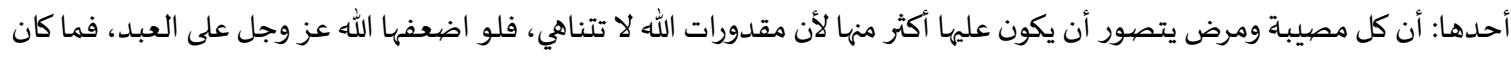

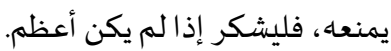
الثاني: أن المصيبة لم تكن في الدين: قال عمر بن الخطاب رضي الله عنه: ما ابتليت ببلاء إلا كان لله عليَّ فيه اربع نَعَمٍ، إذ لم يكن في ديني، وإذ لم يكن أعظم وإذ لم أحرم الرضا باه، وإذ ارجوا الثواب عليه. الثالث: أنَّ ما من عقوبة إلا كان يتصور أن تؤخر إلي الآخرة، ومصائب الدنيا يتسلى عنها فتخفف، ومصيبة الآخرة دائمة، وإن لم تدم فلا

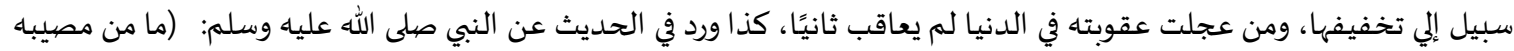

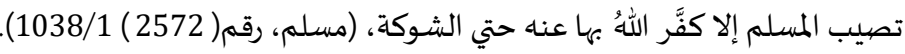

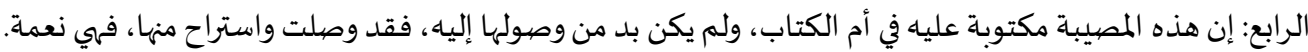
الخامس: ان ثوابها أكثر منها:

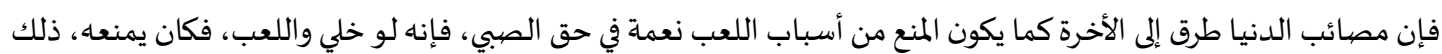

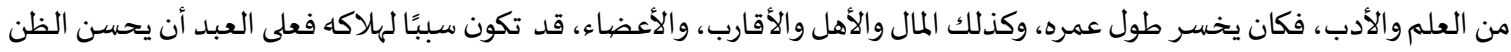

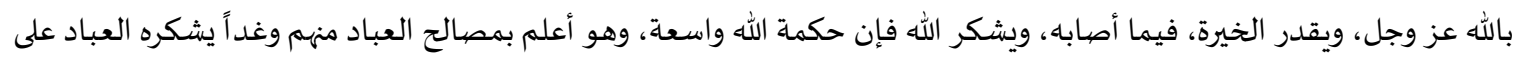

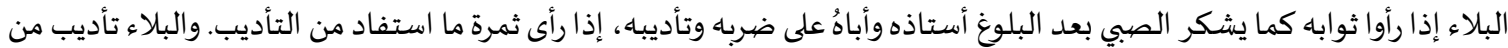

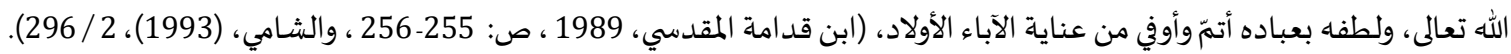
وفي الحديث (لا يقضي الله للمؤمن قضاء إلا كان خيرًا له، (ابن حنبل، 117/3).

القواعد التي يقوم عليها الشكر:

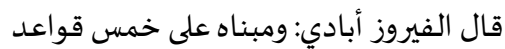
1 2. 3. أعترافه بنعمته 4. الثناء علياء بها

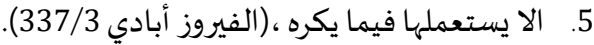

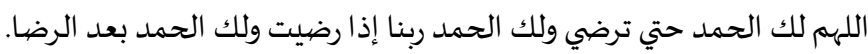
ثانياً: مقام الرضا:

وهو المقام الثاني بعد الشكر ومعني الرضا بالمصيبة أن يستأنس لها ويعلم انها خير له ويرضى بها في داخله يسلم لها ولا يجد في قلبه رغبة أن لا تكون جاءته، وقد وردت النصوص في فضل الن الرضا في الكتاب والسنة فنذكر منها: أولًا: من القرآن الكريه:

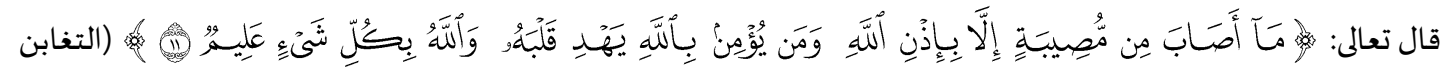

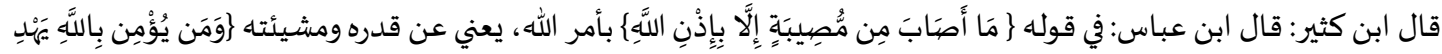

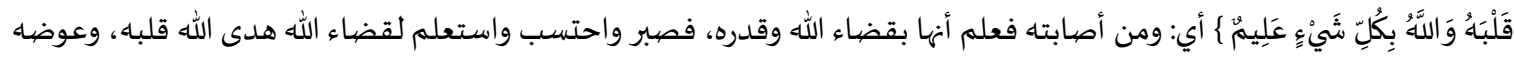

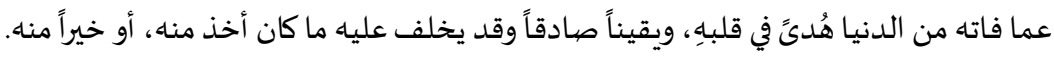




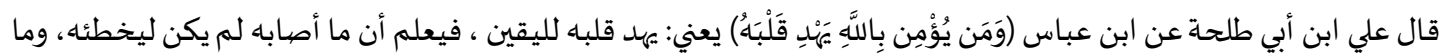

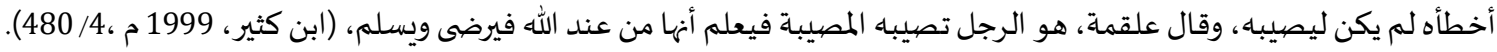

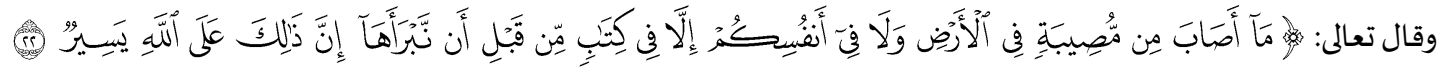

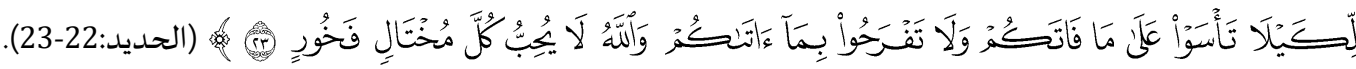

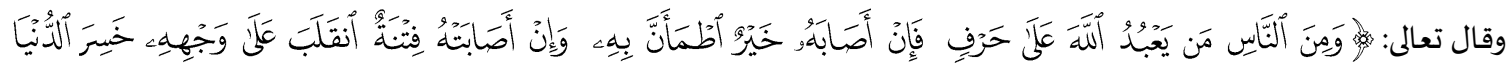

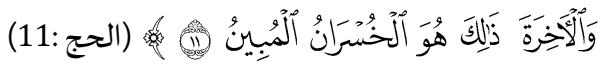

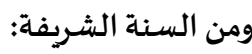
عن أنس بن مالك رضي الله عنه عن النبي صهلى الله عليه وسلم قال: (عِظم الجزاء مع عِظم البلاء وإن الله إذا أحب قوما أبتلاهم

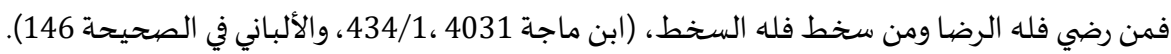

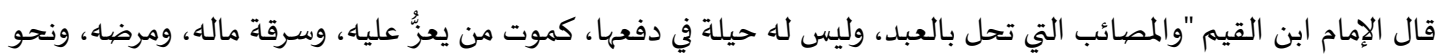

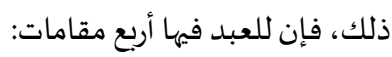
أحدها: مقام العجز، وهو مقام الجزع والشكوى والسخط، وهذا مان الشا لا يفعله إلا أقل الناس عقلاً وديناً ومروءة.

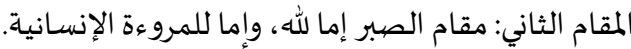

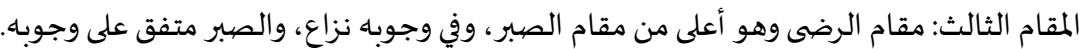

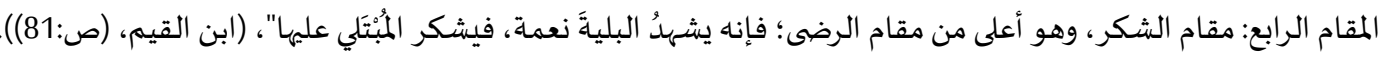

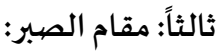
تعريف الصبر:

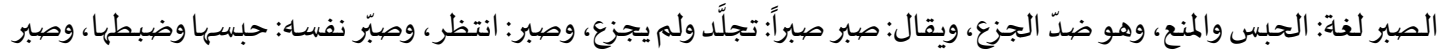

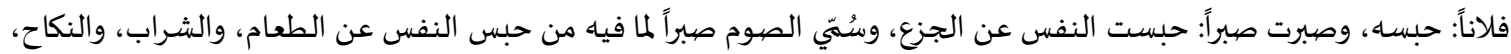

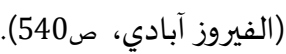

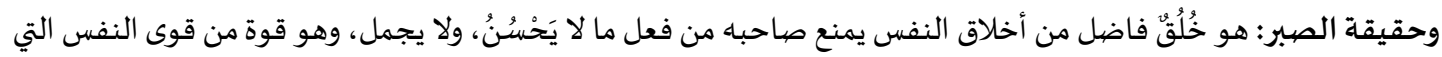

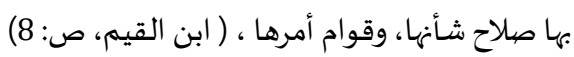

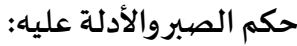

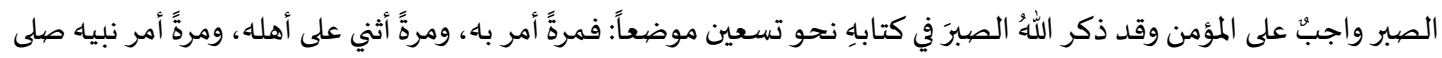

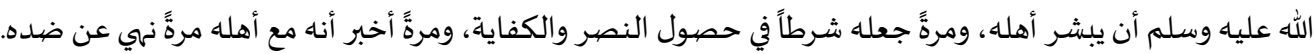

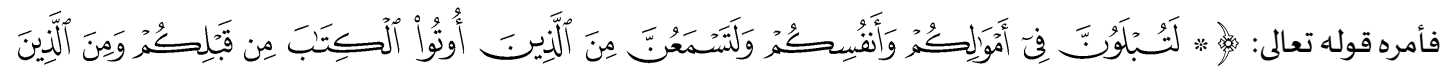

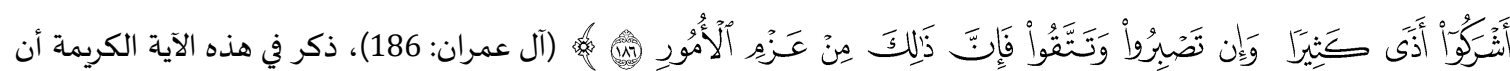

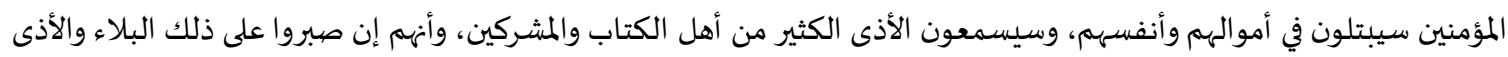

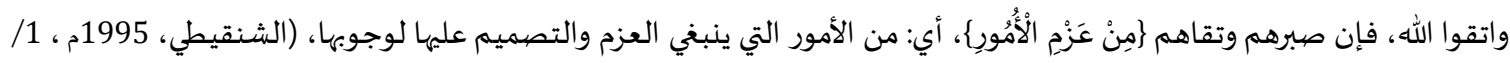

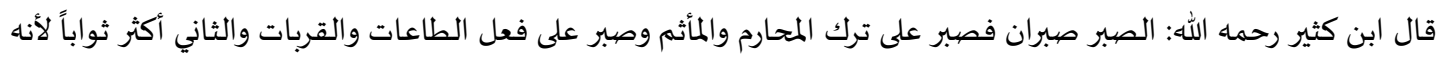

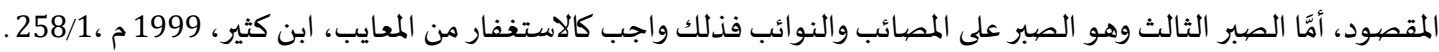

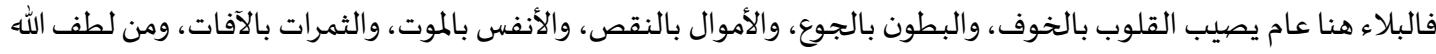

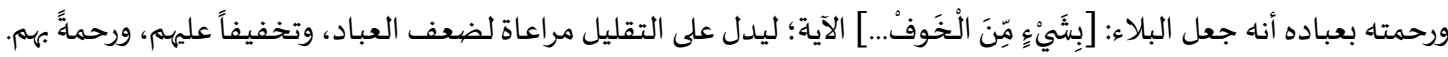

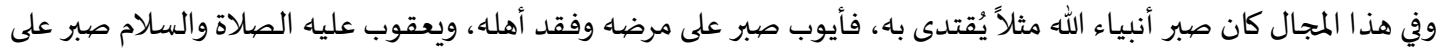

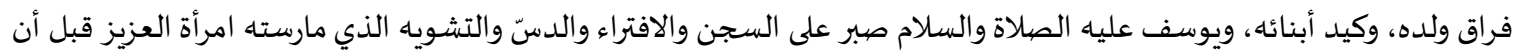

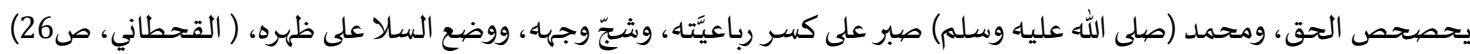
رابعاً: مقام السخط والجزع:

والسخط والجزع مذموم في الشرع وفي العقل أما في الشرع للأدلة الآتية منها في القرآن الكريم: 


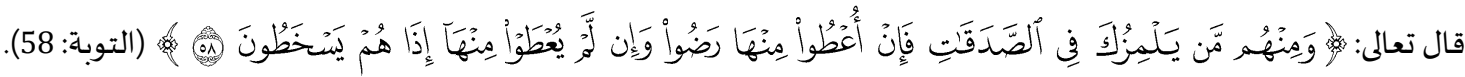

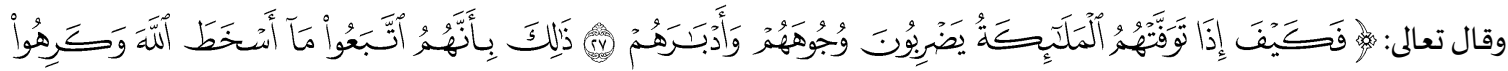

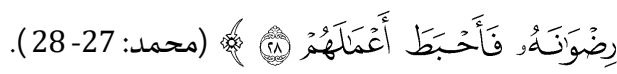

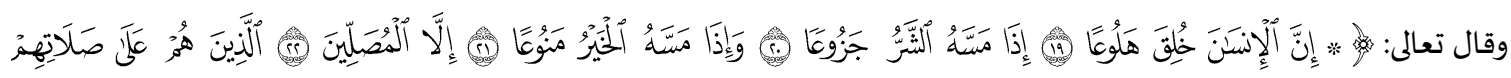

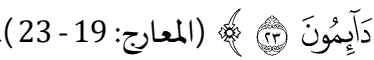

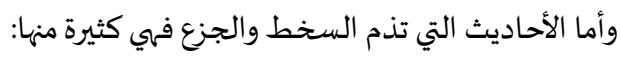

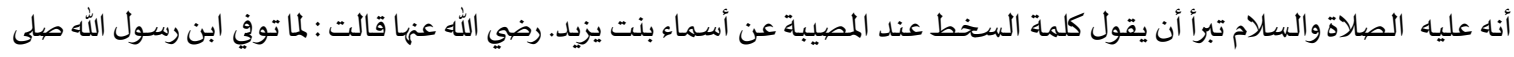

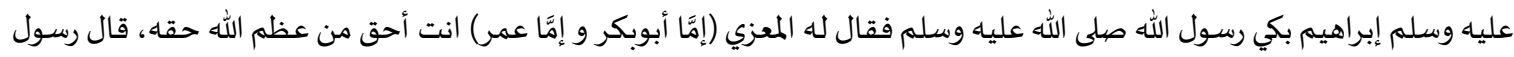

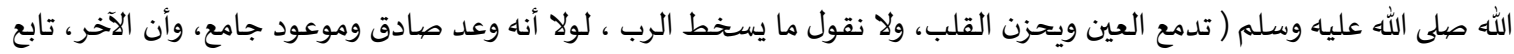

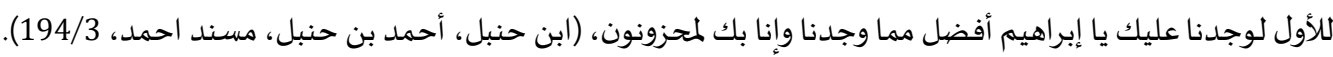

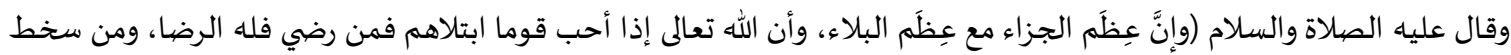

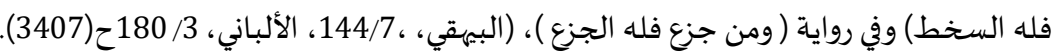

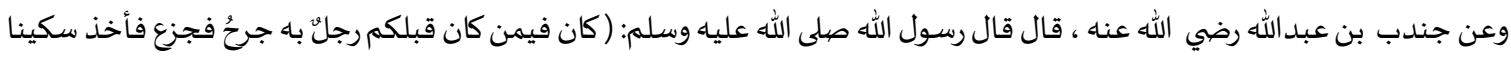

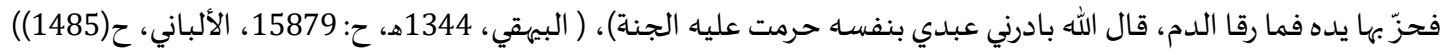

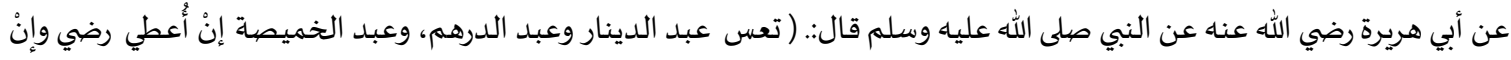
لم يعط سخط )، (البخاري، (2887) (555/1).

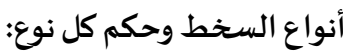

أن يكون (السخط) بالقلب كأن يسخط على ربه، ويغتاظ مما قدره الله عليه فهذا حرام وقد يؤدي إلى الكفر قال تعالى: هوَّمَنَ

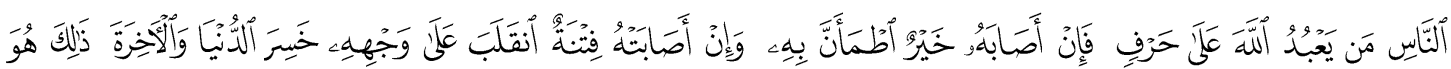

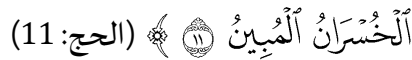

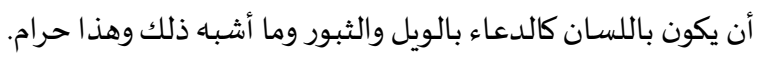
أن يكون بالجوارح كلطم الخدود، وشق الجيوب ، ونتف الشعور، وما أشبه ذلك وكل هذا بالحرام الشعام مناف للصببر.

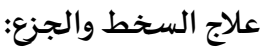

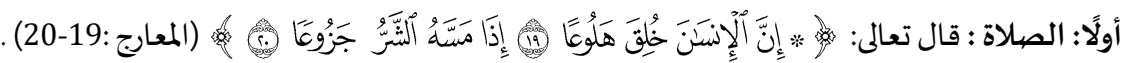

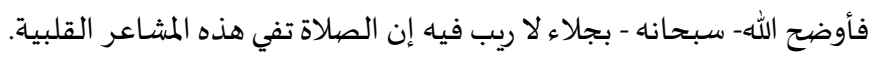

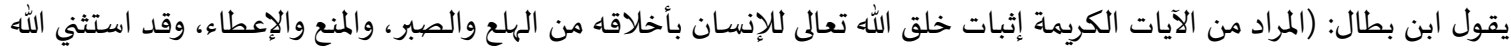

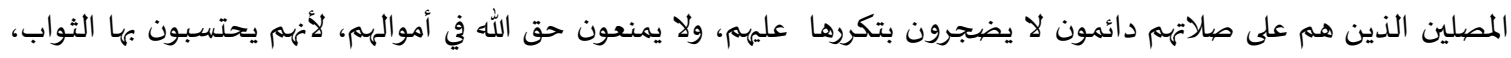

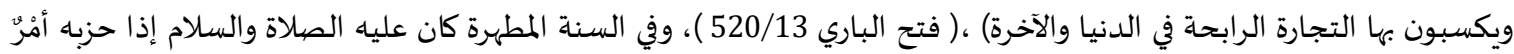

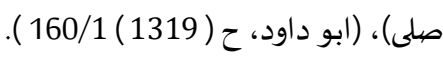

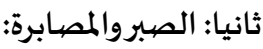
عن أبي سعيد الخدري رضي الله عنه: أن ناسا من الأنصار سالوا رسول الله صهلى الله عليه وسلم، فأعطاهم، ثم سألوه، فأعطاهم،

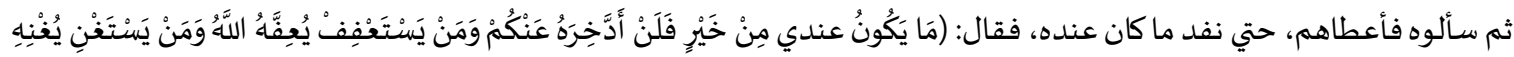

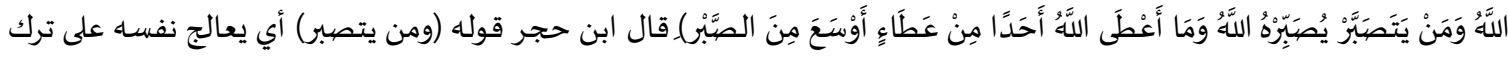

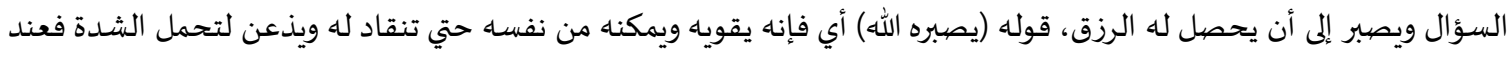

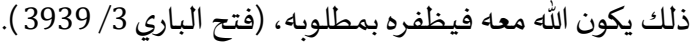


ثالثاً: الإيمان بالقضياء والقدر:

فإن الإيمان بالقضاء، والقدر، يعالج الجزع، والسخط، والقنوط، واليأس، قال عليه الصلاة والسلام: (إنك لن تجد طعم الإيمان

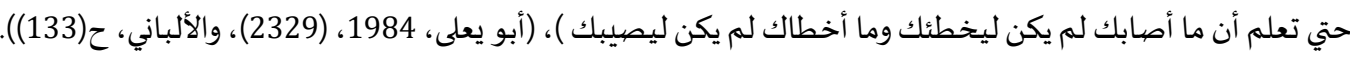

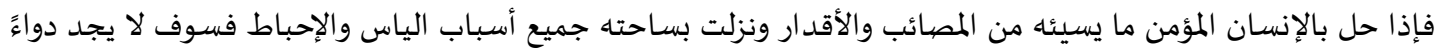

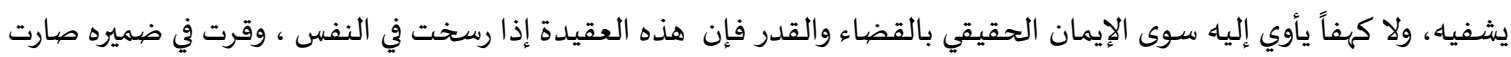

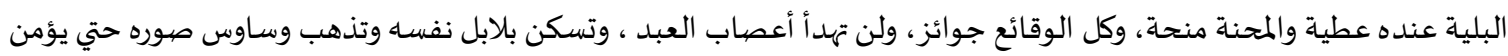

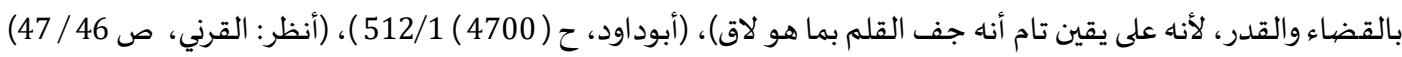

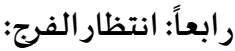

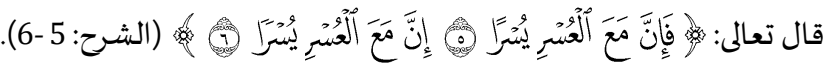
وقال عليه الصلاة والسلام: (وأعلم أن النصر مع الصبر وأن الفرج مع الكرب)، (أحمد 307/1 ، والألباني، ح(2382) ).

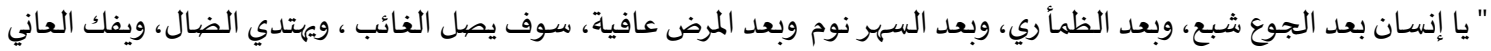

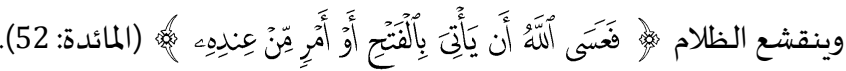

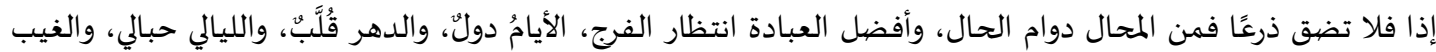

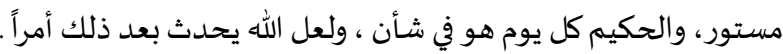
المطلب الثاني: فو ائد التربوية من الابتلاء

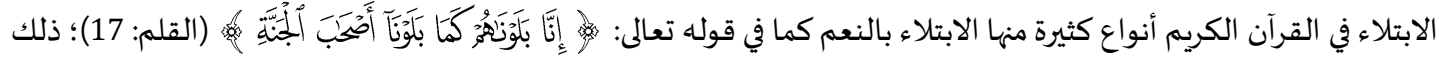

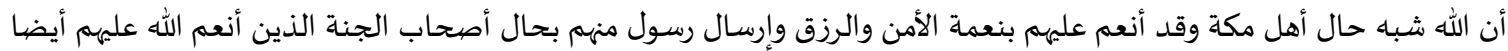

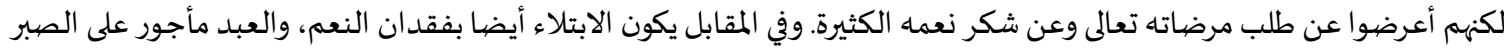

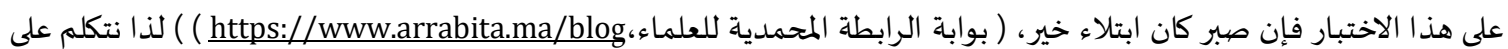

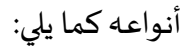
النوع الأول: الابتلاء بالتكليف وفو ائده: إن في بعض الابتلاءات استدعاء للطاعة وامتثال لأوامر الله، بل إن مصلحة الطاعة والامتثال والمسارعة إلههما هي الحكمة الأولى المبتغاة من وضع الشريعة، (وزارة الأوقاف والشئون الإسلامية، الكويت، 12/ 204)، بل من الخلق في أساسه، قال الله تعالى: ولهَ ومَا

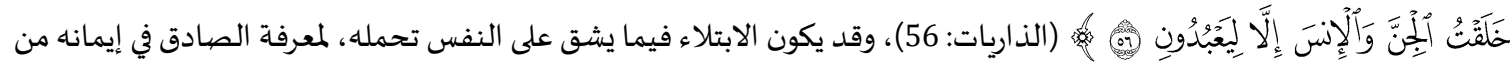

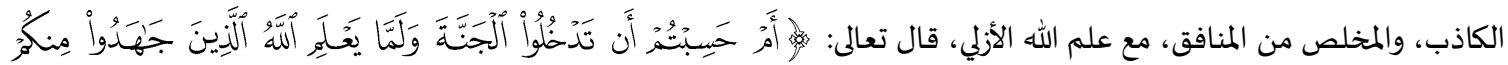

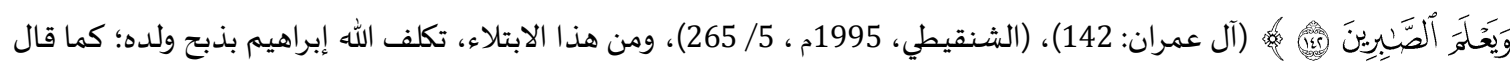

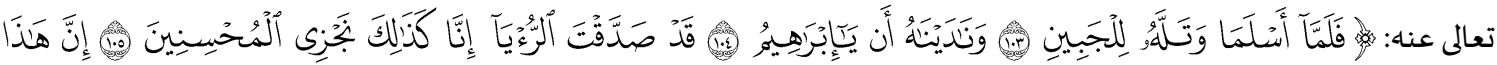

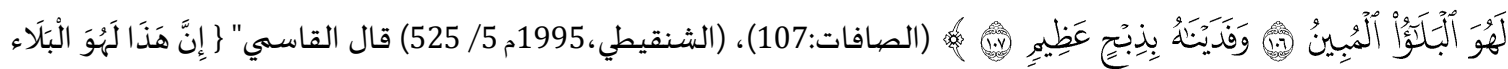

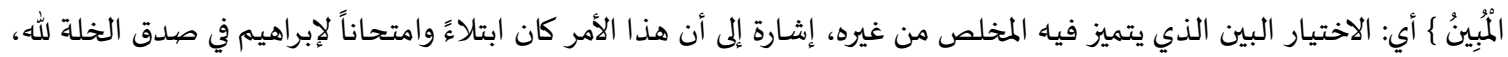

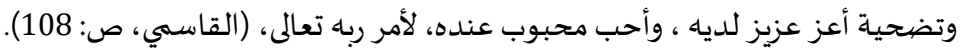

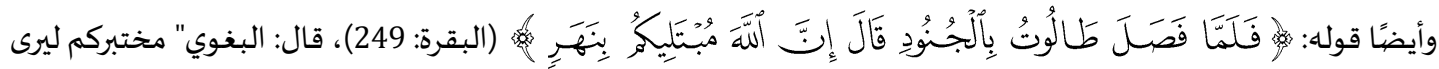

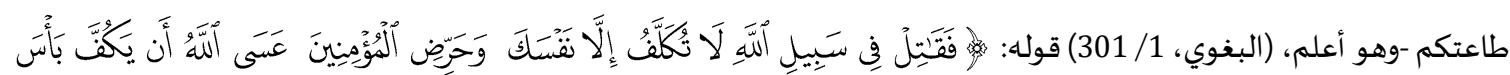

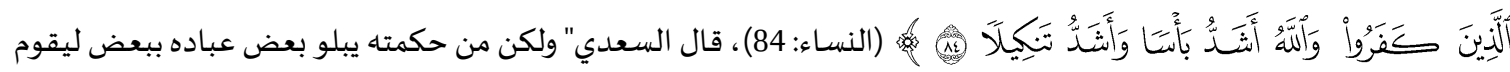

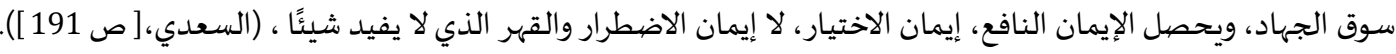




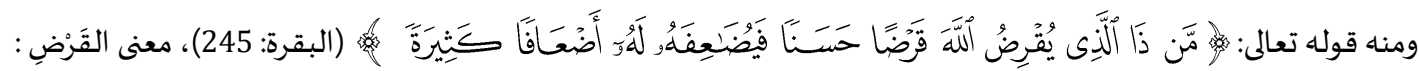

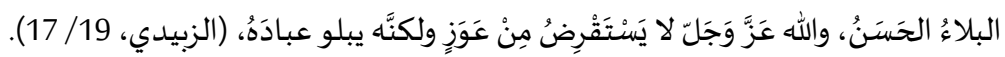
فالفائدة التربوية من التكليف بالطاعة معرفة الصادق في الإيمان.

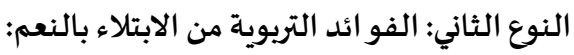
يستوجب الشكر ويستعملها في مرضاة الله:

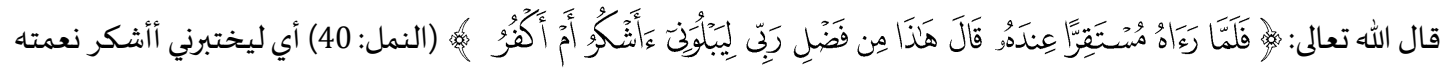

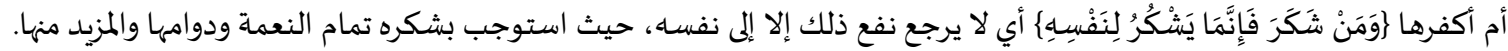

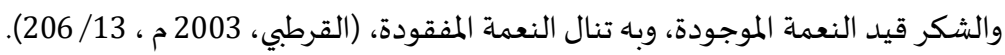

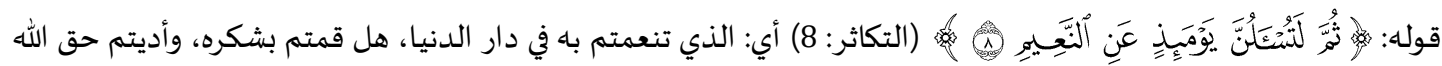
فياء، ولم تستعينوا باه، على معاصياه، فينعمكم نعيمًا أعلى منهاه وأفضل.أم اغتررتم باه، ولم تقوموا بشكره؟ بل ربما استعنتم باه على

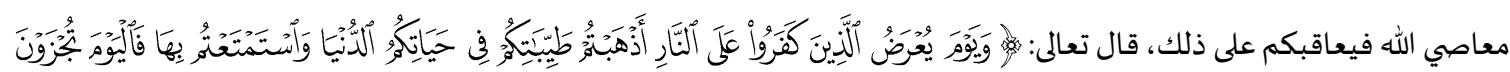

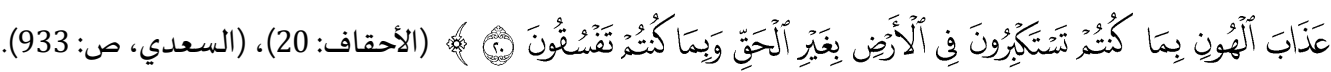

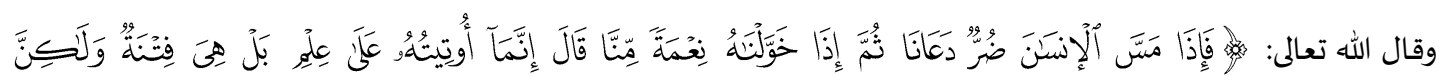

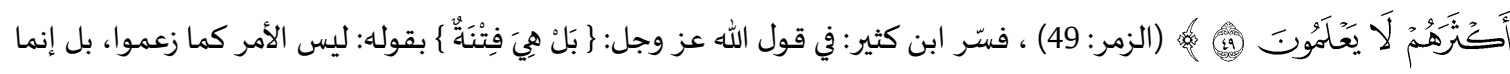

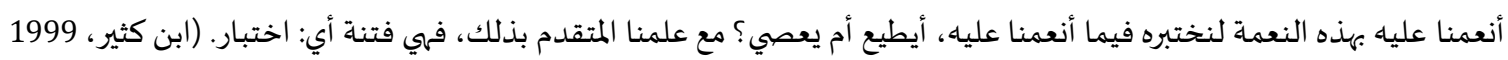

م، 105/ (105).

• ق قد يكون استدراج، فيستوجب الخوف من مكر الله:

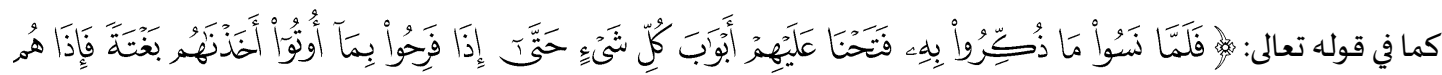

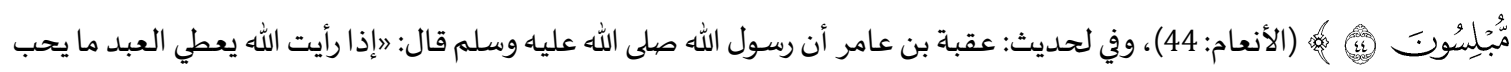

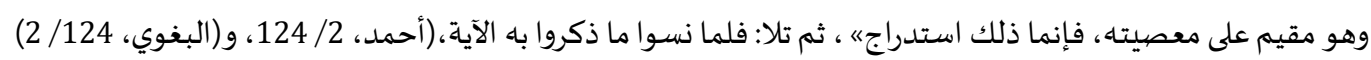

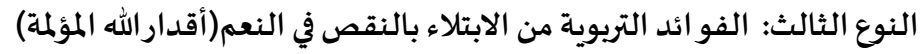
• • • العادة من الابتلاء للصالحين رفعة لدرجاتهم:

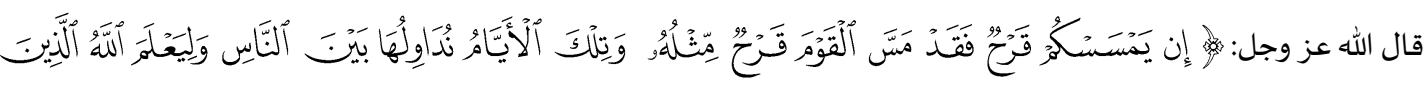

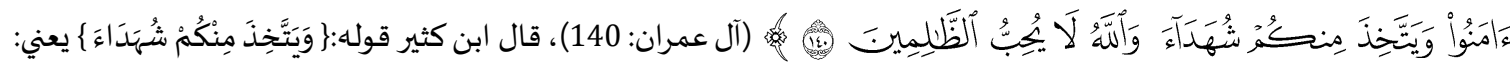

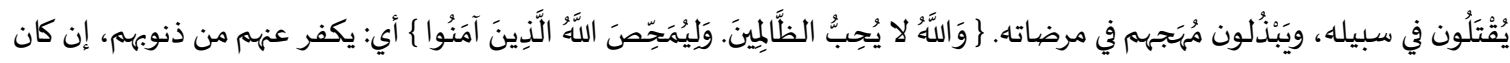

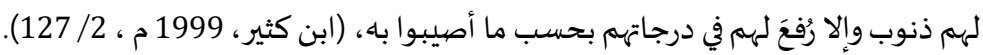
•

قال الله تعالى: من الله سبحانه لرسوله صلى الله عليه وسلم والمعنى أن الله سبحانه جعل لكل نبي من الأنبياء الداعين إلى الله عدوا يعادياء من مجرمي

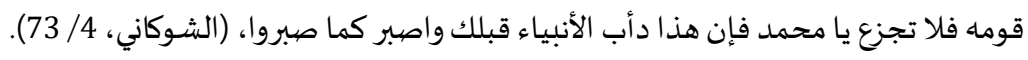
قد يكون عقوبة على تقصير، فيستوجب التوبة والرجوع:

وقد وصفف سبحانها بعض خلقها بقوله:

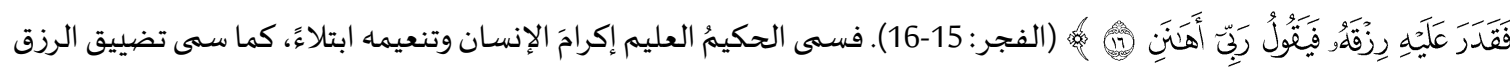
علياء ابتلاءً، وذَذَّ من يجزم بأن ما يصيبه من الله تعالى من الإكرام إكرامًا، كما ذمّ من يجزم بأن ما أصابه من تضييق الرزق هوانا، سواء 
بسواء، وذلك لأن العبد ليس مأمورًا باستكشاف الغيب وشغل نفسها به، بل مأمور في جميع الأحوال بالطاعة والخشية، (الوسطية في

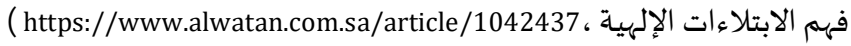
قال تعالى مسلياً ومعزياً ومؤسياً لهذا النبي الكريم ( صلى الله عليه وسلم) بمن تقدمه من إخوانه الأنبياء والمرسلين، مذكراً له بما قاسوا

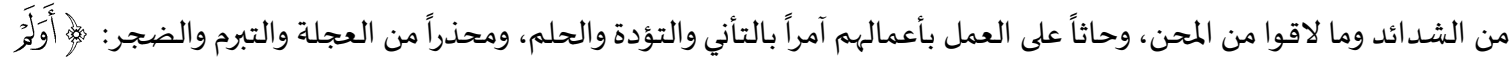

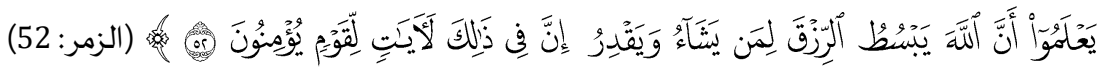

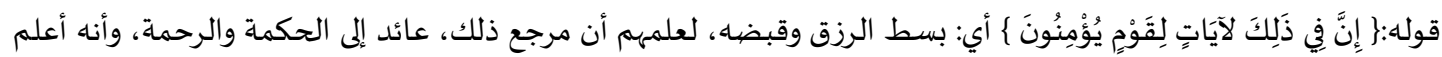

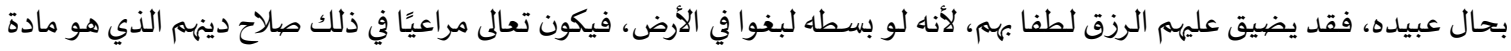

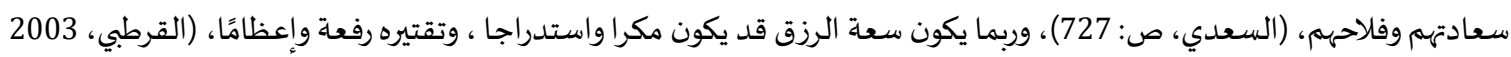

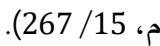

النوع الر ابع فو ائد الابتلاء بالصبر عن المعصية:

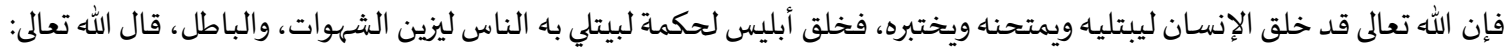

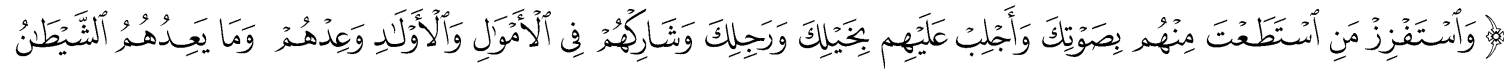

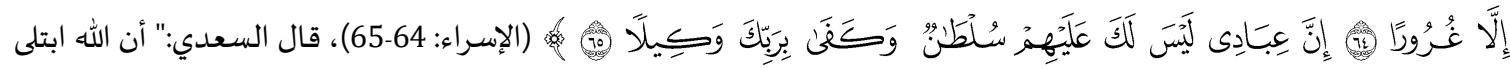

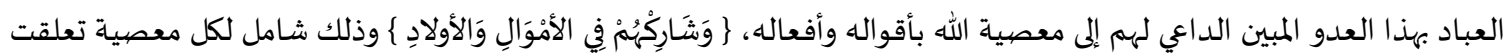

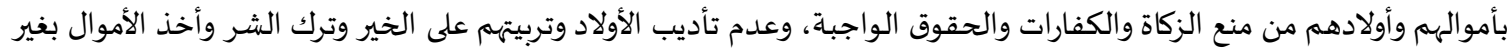

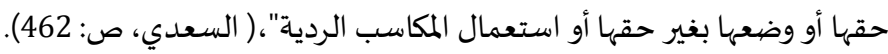

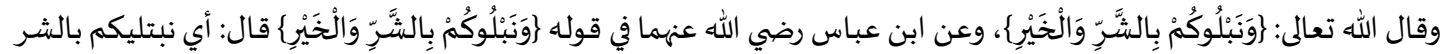

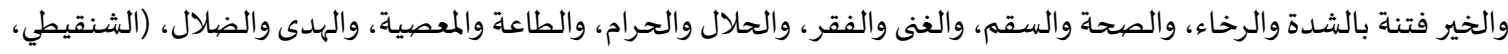

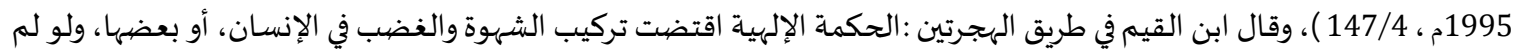

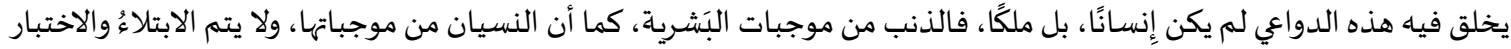

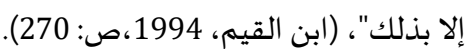

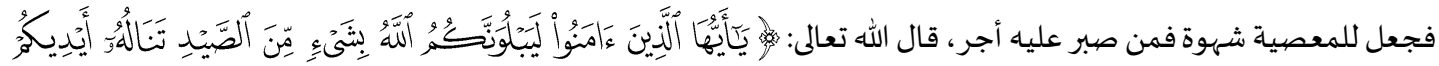

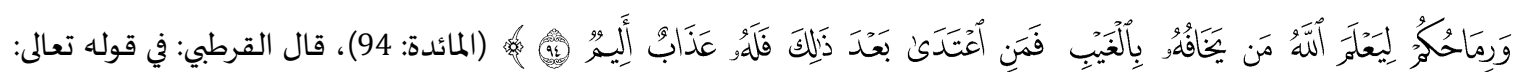

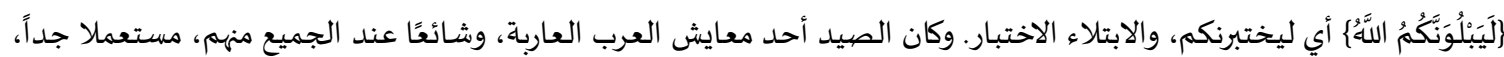

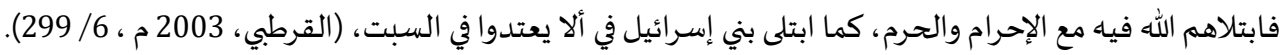

الخاتمة: وتشتمل على أهم النتائج والتوصيات:

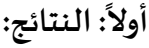
ومن أهم النتائج التي توصلت إلهها في هذا البحث: إنّ مفهوم الابتلاء هو استخراج ما عند المبتلى وتعرف حاله في الطاعة والمعصيية، وهو مرتبط بحياة الإنسان فما دامت هناك حياة فهناك حتماً ابتلاء. إنّ معاني الابتلاء، في القرآن الكريم، بمعنى الامتحان، وبمعنى الفتنة، والتمحيص، والتكليف، ويتبين لنا أن هذه الكلمات تلتقي في معنىً واحٍِ هو الاختبار والامتحان. إن أعلى مقامات الناس عند الابتلاء هم أهل الشكر ، ثمّ أهل الرّضضا، ثمّ الصيّابرون. إن البلاء قد يقع بالمنحة وقد يقع بالمحنة، وأنه إن لم يكن في الدّين فهو هيّن. أن الهدف الأساسي من التحلي بخلق الصبر هو كسب رضا الله-عز وجل-. 
إن للبلاء فوائد تربوية تعود على المرء في دينه ودنياه وآخرته إذا صبر وحمد واسترجع واحتسب، ومن أجل ما فيه معيّة الله عز وجل في الدنيا ورضهوانه في الاخرة.

أن الابتلاء درس تربوي عملي، بتربية النفوس على صبر الطاعة، وتحمّل كبد الدنيا، والرضا والقناعة بالكسب والرزق.

ثانياً: التوصيات:

يُوِي هذا البحث بعناية المتخصصين بالدراسات القرآنياة، دراسة الآيات التي تتعلق بالصبر، الرّضا، وما يناقضهاه من الجزع والسّّخط، ومعرفة هد اياتها وإخراجها في شكل بحوث وأوراق علمية لتعم الفائدة.

المصيادروالمراجع:

أولاً: القرآن الكريم

ثانياً: الكتب والمصهادر: ألمرن

1.

2. الأنس، ر. سُنَّة الابتلاء في القرآن الكريهم. فلسطين: جامعة النجاح الوطنية، ماجستير، أصول الدين بكلية الدراسـات العليا .

3. البغوي، ا. معالم التننيل. المدينة النبوية، دار طيبة للنشر النشر والتوزيع.

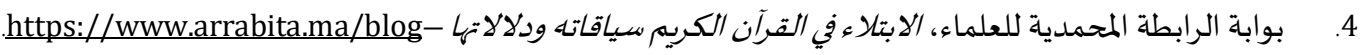

5. البيهقي، أ.(1344هـ) السنن الكبرى،طوابه، حيدر آباد: مجلس دائرة المعارف النظامية .

6.

7.

8. الزبيدي، م. تاج العروس من جواهر القاموس. دار الهداية .(المكتبة الشاملة)

9 9.

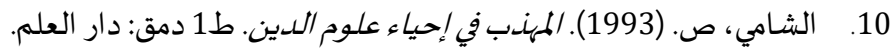

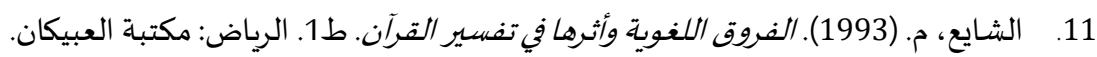

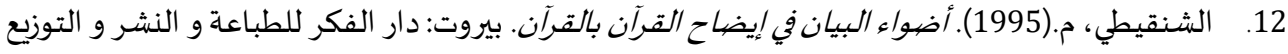

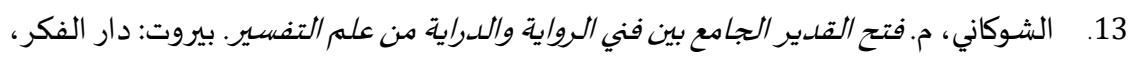

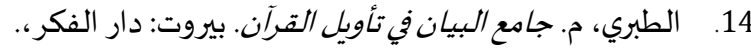

$$
\begin{aligned}
& \text { 15. ابن عاشور ، م. التحير والتنوير. الطبعة التونسية، م. ت. ت. }
\end{aligned}
$$

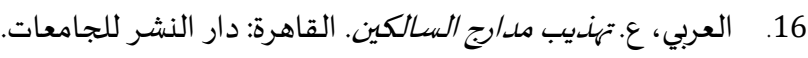

17.

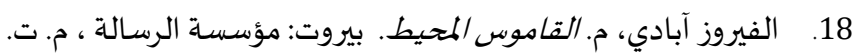

19. القاسمي، م. محاسن التأويل. المكتبة الشاملة.

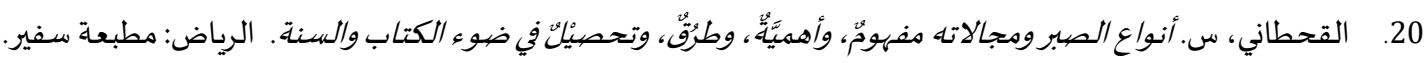

21. أبن قدامة أ. (1989). مختصبر منهاج القاصيلدين. ط ط1 القاهرة: دار التراث العربي .

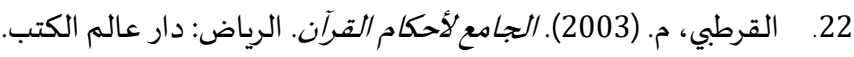

23. القرني، ع. (2009)، لا تحزن. ط 11. الرياض: مكتبة العبيكان

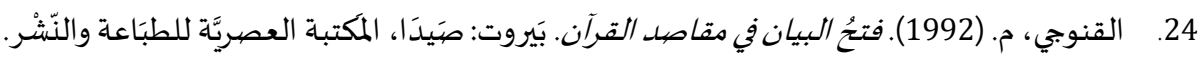

25. ابن القيم، م. طريق الهجرتين وباب السعادتين. الدمام : دار ابن القيم، م. ت. ت.

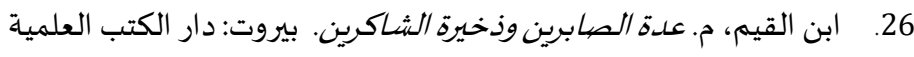

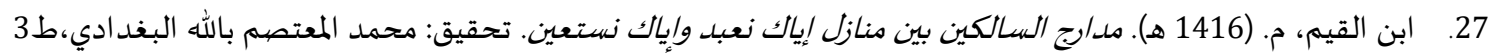

بيروت: دار الكتاب العربي.

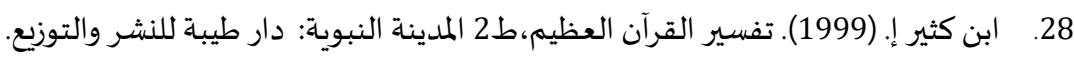

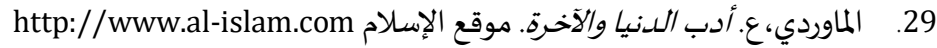


30. مسلم ،م. صحيح مسلم. بيروت، دار إحياء التراث العربي تحقيق: محمد فؤاد عبد الباقي.

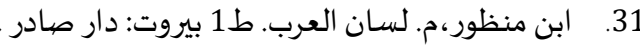
32. أبو هلال العسكري ا. (1980). الفروق في اللغنة. ط4، بيروت: إحياء التراث العربي، دار الآفاق الجديدة. 33. وزارة الأوقاف والشئون الإسلامياة، الموسوعة الفقهية الكويتية، ط2. الكويت: دار السلاسل .

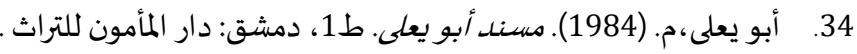




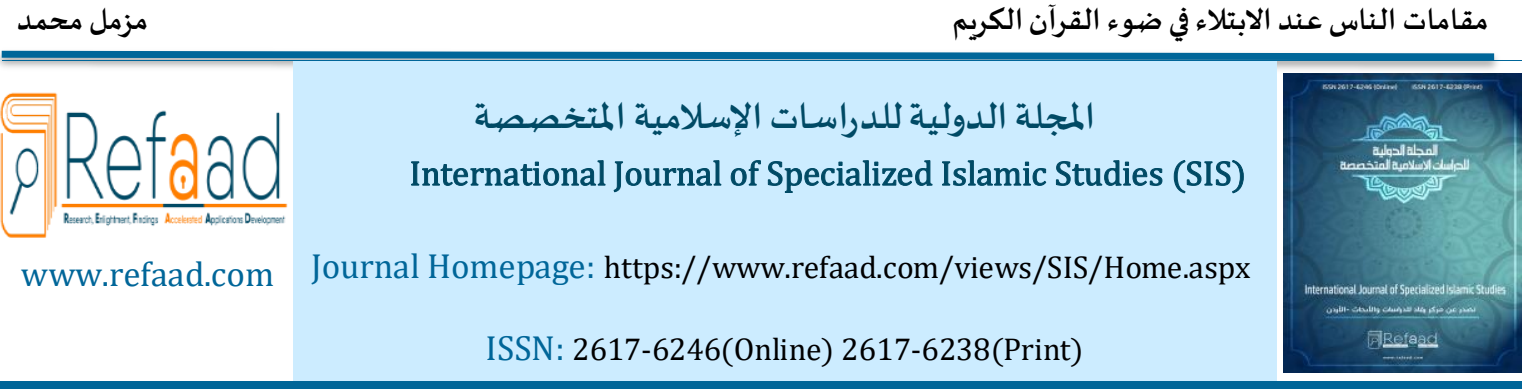

\title{
People variation at tribulation from the perspective of the holy Quran
}

\author{
Muzamil Mohamed Abdi Mohamed \\ Assistant Professor of Interpretation, Imam Al-Mahdi University, Sudan \\ mozamil.abdeen194@gmail.com
}

Received: 26/9/2021 Revised: 3/10/2021 Accepted: 5/10/2021 DOI: https://doi.org/10.31559/SIS2021.6.1.4

\begin{abstract}
This research is titled Maqamat al-Maqāmat al-unah when calamity is in the light of the Noble Qur'an. The research aimed to shed light on knowledge of people's homes, and their disparity with affliction, and then deduced the most important educational aspects of the affliction. Whether the affliction was a gift or an ordeal, and the study tried to answer the following questions: What is the concept of affliction? What are the similar terms in the Holy Qur'an and their implications, what are the educational benefits of the affliction? To achieve this goal, the researcher followed the inductive and deductive approach, whereby the researcher presented the Qur'anic verses that dealt with the issue of affliction, and then deduced the most prominent educational values learned from those verses that contain the affliction.

To achieve this goal, the researcher took the inductive and deductive approach, whereby the researcher presents the Qur'an verses that dealt with the issue of affliction, then deduces the most prominent educational values learned from those verses that contain affliction. In the place of honor, they are the people of thanksgiving, then the people of satisfaction, then the patient, and that calamity does not occur only through tribulation, but also by grant, and that if it is not in debt, then it is easy.

And among the effects of the affliction is that it makes the Muslim fortified, with determination and patience, so patience and certainty attain the imamate in the religion.
\end{abstract}

Keywords: Maqamat al-Nas, al-Tabla, educational values.

\section{References:}

1. Abn 'ashwr, M. Althryr Waltnwyr. Altb'h Altwnsyh, M. T.

2. Al'rby, '. Thdyb Mdarj Alsalkyn. Alqahrh: Dar Alnshr Lljam'at.

3. Alans, R. Sunh Alabtla' Fy Alqran Alkrym. Flstyn: Jam't Alnjah Alwtnyh, Majstyr, Aswl Aldyn Bklyh Aldrasat Al'lya .

4. Alazhry, M. Thdyb Allghh, Thqyq, Y'qwb Bn 'bd Alnby. Alqahrh: Aldar Almsryh Lltalyf Waltrjmh, Mtab' Sjl Al'rb.

5. Albghwy,A. M'alm Altnzyl. Almdynh Alnbwyh, Dar Tybh Llnshr Waltwzy'.

6. Bwabh Alrabth Almhmdyh Ll'lma', Alabtla' Fy Alqran Alkrym Syaqath Wdlalatha https://www.arrabita.ma/blog.

7. Albyhqy, A. (1344) Alsnn Alkbra, T1 Hydr Abad: Mjls Da'ert Alm'arf Alnzamyh .

8. Abn Fars, A. M'jm Mqayys Allghh, Dar Alfkr., M. T.

9. Alfyrwz Abady, M. Alqamws Almhyt. Byrwt: M'sst Alrsalh, M. T.

10. Abn Hnbl, A. Msnd Ahmd. Alqahrh M'sst Qrtbh, M. T.

11. Abw Hlal Al'skry A. (1980). Alfrwq Fy Allghh. T4, Byrwt: Ehya' Altrath Al'rby, Dar Alafaq Aljdydh.

12. Abn Kthyr E. (1999). Tfsyr Alqran Al'zym, T2 Almdynh Alnbwyh: Dar Tybh Llnshr Waltwzy'.

13. Almawrdy,'. Adb Aldnya Walakhrh. Mwq' Aleslam. http://www.al-islam.com

14. Abn Mnzwr,M. Lsan Al'rb. T1 Byrwt: Dar Sadr. 
15. Mslm, M. Shyh Mslm. Byrwt, Dar Ehya' Altrath Al'rby Thqyq: Mhmd F'ad 'bd Albaqy.

16. Alqasmy, M. Mhasn Altawyl. Almktbh Alshamlh.

17. Alqhtany, S. Anwa' Alsbr Wmjalath Mfhwmun, Wahmyhun, Wtruqun, Wthsylun Fy Dw' Alktab Walsnh. Alryad: Mtb't Sfyr.

18. Abn Qdamh A. (1989). Mkhtsr Mnhaj Alqasdyn. T1 Alqahrh: Dar Altrath Al'rby .

19. Alqrtby, M. (2003). Aljam' Lahkam Alqran. Alryad: Dar 'alm Alktb.

20. Alqrny, '. (2009), La Thzn. T 11. Alryad: Mktbt Al'bykan

21. Alqnwjy, M. (1992). Fthu Albyan Fy Mqasd Alqran. Byrwt: Sýdá, Almktbh Al'sryh Lltbá'h Walnshri.

22. Abn Alqym, M. Tryq Alhjrtyn Wbab Als'adtyn. Aldmam: Dar Abn Alqym, M. T.

23. Abn Alqym, M. 'dh Alsabryn Wdkhyrh Alshakryn. Byrwt: Dar Alktb Al'lmyh

24. Abn Alqym, M. (1416 H). Mdarj Alsalkyn Byn Mnazl Eyak N'bd Weyak Nst'yn. Thqyq: Mhmd Alm'tsm Ballh Albghdady, T3 Byrwt: Dar Alktab Al'rby.

25. Alraghb Alasfhany A. Almfrdat Fy Ghryb Alqran. Thqyq Mhmd Syd Kylany, Lbnan: Dar Alm'rfh.

26. Als'dy, 'E. (1973). Tysyr Alkrym Alrhmn Fy Tfsyr Klam Almnan. Byrwt: M'sst Alrsalh.

27. Alshamy, S. (1993). Almhdb Fy Ehya' 'lwm Aldyn. T1 Dmq: Dar Al'lm.

28. Alshay', M. (1993). Alfrwq Allghwyh Wathrha Fy Tfsyr Alqran. T1. Alryad: Mktbt Al'bykan.

29. Alshnqyty, M. (1995). Adwa' Albyan Fy Eydah Alqran Balqran. Byrwt: Dar Alfkr Lltba'h W Alnshr W Altwzy'.

30. Alshwkany, M. Fth Alqdyr Aljam' Byn Fny Alrwayh Waldrayh Mn 'lm Altfsyr. Byrwt: Dar Alfkr,

31. Altbry, M. Jam' Albyan Fy Tawyl Alqran. Byrwt: Dar Alfkr,

32. Wzart Alawqaf Walsh'wn Aleslamyh, Almwsw'h Alfqhyh Alkwytyh, T2. Alkwyt: Dar Alslasl.

33. Abw Y'la,M. (1984). Msnd Abw Y'la. T1, Dmshq: Dar Almamwn Lltrath.

34. Alzbydy, M. Taj Al'rws Mn Jwahr Alqamws. Dar Alhdayh .(Almktbh Alshamlh). 